\title{
Purified Neonatal Plasmacytoid Dendritic Cells Overcome Intrinsic Maturation Defect with TLR Agonist Stimulation
}

\author{
MARIELLE C. GOLD, ERIN DONNELLY, MATTHEW S. COOK, CATHERINE M. LECLAIR, AND DEBORAH A. LEWINSOHN \\ Department of Pediatrics [M.C.G., E.D., M.S.C., D.A.L.], Department of Obstetrics and Gynecology [C.M.L.] Oregon Health and Science \\ University, Portland, OR 97239
}

\begin{abstract}
Neonates are more susceptible than adults to viral and bacterial diseases. We hypothesized that plasmacytoid dendritic cells, the cells that provide large amounts of IFN- $\alpha$ in response to Toll-like receptor 9 (TLR9) agonists, are defective in neonates. To assess the intrinsic functionality of plasmacytoid dendritic cells from neonates we compared IFN- $\alpha$ production by plasmacytoid dendritic cells derived from neonates versus adults in both whole blood and in purified plasmacytoid dendritic cells. TLR9-stimulation of whole blood from adults and neonates resulted in comparable amounts of IFN- $\alpha$ production. However, we observed small but significant differences in IFN- $\alpha$ production from purified CD123+ plasmacytoid dendritic cells from neonates after stimulation with the TLR9 ligand CpG-DNA. Furthermore, we assessed surface expression of costimulatory molecules on plasmacytoid dendritic cells after stimulation. While purified CD123+ plasmacytoid dendritic cells from adults up-regulated co-stimulatory molecules CD80 and CD86 with IL-3 alone those from neonates required the addition of CpG-DNA to reach adult levels. Therefore, the intrinsic deficiencies of neonatal plasmacytoid dendritic cells can be mitigated by TLR9 agonists. These results are consistent with the observation that vaccines that effect strong adjuvant activity on dendritic cells can induce protective responses in neonates. (Pediatr Res 60: 34-37, 2006)
\end{abstract}

$\mathrm{N}^{\mathrm{e}}$ eonates are more susceptible than adults to severe disease following exposure to viruses and bacteria (1). A lack of pre-existing memory $\mathrm{T}$ - and $\mathrm{B}$-cells as well as diminished T-cell responses (2), reduced numbers of dendritic cells (DC), and a bias toward Th2 immunity (3) are contributors, but likely don't entirely explain this observation. One hypothesis is that neonatal DC are functionally immature. One manifestation of such immaturity may be that neonatal DC respond suboptimally to pathogens via Toll-like receptor (TLR) agonist stimulation and therefore are lacking the ability to provide a link between innate and adaptive immune responses (4). Unlike myeloid DC, plasmacytoid DC (pDC) express high levels of the pathogen-recognizing receptor TLR9 (4). Once stimulated with TLR9 agonists such as viral $(5,6)$ as well as bacterial DNA $(7,8)$ pDC produce large amounts of IFN- $\alpha$. In addition, $\mathrm{pDC}$ can stimulate allogeneic T-cells and pDC exposed to virus are capable of directly priming $\mathrm{T}$-cells in mice

Received September 19, 2005; accepted February 11, 2006.

Correspondence: Deborah A. Lewinsohn, M.S., Department of Pediatrics CDRC-P, 3181 SW Sam Jackson Park Road, Oregon Health and Science University, Portland, OR 97239; e-mail: lewinsde@ohsu.edu

Funding source: 5R01 AI054474.
(9). Furthermore, influenza-exposed pDC can stimulate antigen-experienced influenza-specific CD4 and CD8 T-cell clones to produce IFN- $\gamma$ suggesting a role for $\mathrm{pDC}$ in stimulation of memory T-cell responses (10).

We hypothesized that DC from the plasmacytoid subset in human neonates were functionally defective. Previous studies of DC either in vivo or using mixed cell populations that contained nonDC $(11,12)$ showed that neonatal DC may be defective while more recent studies using purified populations $(13,14)$ showed DC have little to no intrinsic functional defects. Therefore, to distinguish intrinsic deficiencies from extrinsic factors we studied responses in whole blood and in highly purified pDC from adults and neonates. We assessed the ability of pDC to mature and produce IFN- $\alpha$ in response to TLR9 agonists. We found that measurable differences exist in neonatal pDC but that ultimately these cells have high functional capacities after TLR9 stimulation.

\section{METHODS}

Human subjects. All blood from donors was obtained under protocols approved by the Institutional Review Board at Oregon Health and Science University. Informed consent was obtained from all adult donors. Umbilical cord blood was obtained from healthy full-term neonates under an exempt protocol for informed consent. Cord blood was collected in BD Vacutainer CPT and processed per the manufacturer's instructions. Both fresh and cryopreserved cells were used with equivalent results (data not shown). PBMC were obtained from normal adult donors by apheresis.

Isolation and assessment of pDC. Plasmacytoid DC were isolated using BDCA-4 coated magnetic beads per the manufacturer's instructions (Miltenyi Biotec). Flow cytometry was used to assess expression of co-stimulatory molecules, and confirm purity of sorted cells. Plasmacytoid DC were defined by the lack of cell surface expression of lineage markers (CD3, 14, 16, 19, 20, 56), positive expression of HLA-DR and high expression of CD123 $(15,16)$. Detection of TLR9 was performed on fixed and permeabilized cells using Cytofix/Cytoperm and Perm Wash reagents (BD Biosciences). Antibodies were purchased from BD Biosciences or eBioscience. Acquisition of flow cytometry data were performed using a FACS Calibur in conjunction with Cell Quest software. All further analyses were performed using FlowJo software.

Stimulation of whole blood. One milliliter of fresh uncoagulated whole blood was incubated at $37 \mathrm{C}$ for $20 \mathrm{~h}$ with IL-3 alone $(10 \mathrm{ng} / \mathrm{mL})(\mathrm{R} \& \mathrm{D})$, IL-3 with CpG-A oligodeoxynucleotide (ODN)-2336 (GGGGACGACGTCGTGGGGGGG) $(50 \mu \mathrm{g} / \mathrm{mL})$, or IL-3 and the negative control for CpG A 2243 (GGGGGAGCATGCTGGGGGGG) $(50 \mu \mathrm{g} / \mathrm{mL})$. IL-3 was added to all

Abbreviations: BDCA, blood dendritic cell antigen; DC, dendritic cell; ODN, oligodeoxynucleotide; pDC, plasmacytoid dendritic cell; TLR, tolllike receptor 
conditions to prevent apoptosis of pDC (15). IFN- $\alpha$ production was determined from the plasma.

Stimulation of purified pDC. BDCA- $4^{+}$-purified pDC (25,000/well) were placed in RPMI with $10 \%$ human serum and $10 \mathrm{ng} / \mathrm{mL}$ IL-3. Purified pDC were stimulated for $20 \mathrm{~h}$ with immunostimulatory DNA, CpG-A 2336 or CpG-B 2006 (TCGTCGTTTTGTCGTTTTGTCGTT) and respective negative controls 2243 or 2137 (TGCTGCTTTTGTGCTTTT GTGCTT ) (Coley Pharmaceuticals) at a final concentration of $6 \mu \mathrm{g} / \mathrm{mL}$. Class-A CpG ODN are potent inducers of IFN- $\alpha$ production while class-B CpG ODN preferentially induce the maturation of $\mathrm{pDC}$ (17).

Detection of IFN- $\boldsymbol{\alpha}$. Human IFN- $\alpha$ was quantified from either plasma or cell culture supernatants by ELISA (PBL Biomedical Labs).

Statistical analyses: To assess differences between adults and neonates we used the Prism software package to perform the Wilcoxon nonparametric analysis for the whole blood studies (due to the wide variance between donors) and the unpaired two-tailed $t$-test for the purified cells analysis.

\section{RESULTS}

While all nucleated cells can produce type I interferons, $\mathrm{pDC}$ are unique in their capacity to produce large amounts of IFN- $\alpha$ in response to viral $(5,6)$ and bacterial DNA $(7,8)$. To first address the question of whether or not $\mathrm{pDC}$ from neonates are intrinsically defective, we studied IFN- $\alpha$ production in whole blood, where many factors might influence pDC function, and from purified pDC. Whole blood samples from 10 adults and 10 neonates were incubated with the potent IFN- $\alpha$ inducing agent $\mathrm{CpG}-\mathrm{A}$. Figure 1 shows that equivalent levels of IFN- $\alpha$ were detected in the plasma of adult and cord blood after stimulation. No statistically significant differences were observed.

We then focused our studies on purified pDC to determine whether any intrinsic deficiencies could be detected. Figure 2 $A$ shows the gating strategy used to assess purity of cells sorted using BDCA-4 magnetic bead selection. Purity was determined from live cells that lacked lineage markers, expressed HLA-DR as well as CD123 (Purity of pDC: adult blood $72.2 \pm 4.5 \%$; cord blood $73.1 \pm 7$ ). We then compared IFN- $\alpha$ production from purified $\mathrm{pDC}$ from adults and neonates in response to two classes of CpG-DNA (Fig. 2B). After addition of the potent IFN- $\alpha$ inducing agent CpG-A 2336, pDC from cord blood produced high levels but statistically significantly less IFN- $\alpha$ - than the adult pDC $(2839 \mathrm{pg} / \mathrm{mL}$ versus $6003 \mathrm{pg} / \mathrm{mL}$ respectively $p<0.05$ ). In contrast, in response to CpG-B 2006, IFN- $\alpha$ production by neonatal $\mathrm{pDC}$ was not significantly different compared with adult pDC.

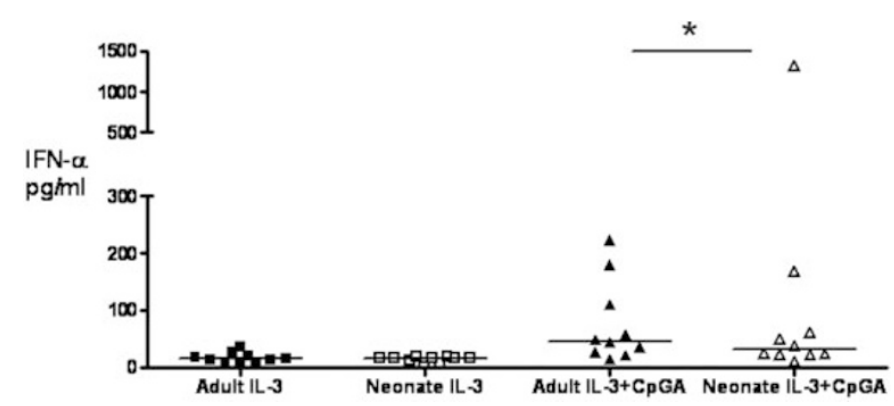

Figure 1. TLR9 stimulation of whole blood from adults and neonates results in comparable levels of IFN- $\alpha$. Whole blood specimens $(1 \mathrm{~mL})$ from adults $(n$ $=10)$ and neonates $(n=10)$ were incubated with IL-3 alone or IL-3 with CpG-A ODN $2336(50 \mu \mathrm{g} / \mathrm{mL})$ for $20 \mathrm{~h}$. IFN- $\alpha$ production was determined by ELISA. ODN 2243 was used as a negative control for CpG-A and never elicited IFN- $\alpha$ levels above IL-3 treatment alone (data not shown). The limit of detection of the IFN- $\alpha$ ELISA is $12.5 \mathrm{pg} / \mathrm{mL}$. * $p=0.275$

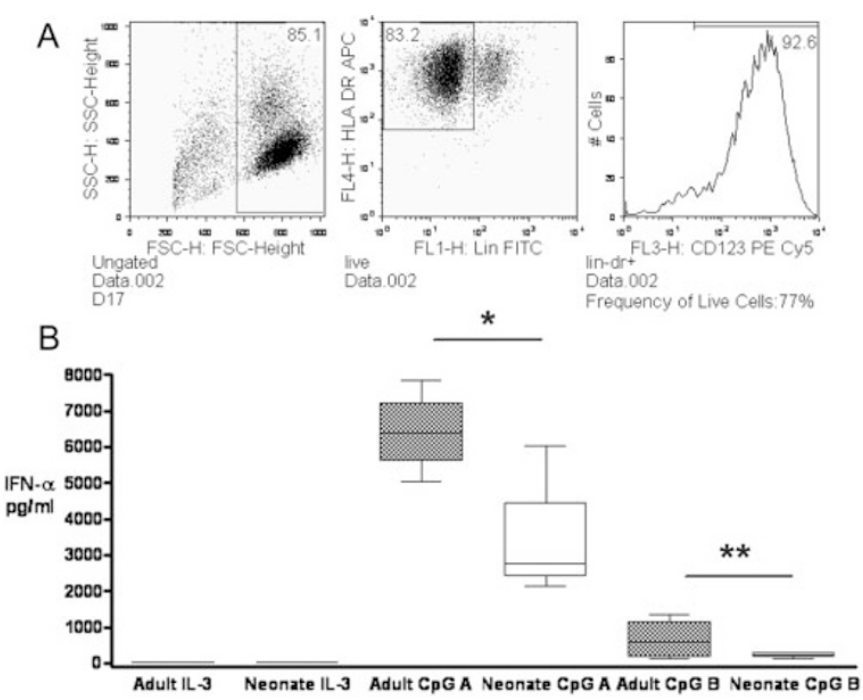

Figure 2. CpG-A, but not $\mathrm{CpG}-\mathrm{B}$ stimulation results in significantly less IFN- $\alpha$ production by purified neonatal pDC. A) Representative plot of the determination of the purity of BDCA-4-selected cells. The percentage of pDC in the BDCA-4 selected cells was based on the following gating strategy: live cells were selected based on the forward and side scatter analysis and subsequently, pDC were defined as lacking lineage markers, expressing HLA-DR, and expressing CD123. $B$ ) IFN- $\alpha$ production from purified pDC from cord blood donors $(n=4)$ and adult donors $(n=4)$ after incubation for $20 \mathrm{~h}$ in IL-3-containing medium with either CpG-A 2336 or CpG-B 2006 DNA. Only treatment with CpG-A showed a significant difference in IFN- $\alpha$ production by the neonatal $\mathrm{pDC}$ compared with adult $\mathrm{pDC}(p<0.05)$. These data are representative of a total of three experiments with a minimum of two donors per group including one experiment in which cells were sorted to $>95 \%$ purity by flow cytometry. ODN 2243 or ODN 2137 were used as negative controls for CpG-A and CpG-B respectively and never elicited IFN- $\alpha$ production by $\mathrm{pDC}$ (data not shown). The limit of detection of the IFN- $\alpha$ ELISA is $12.5 \mathrm{pg} / \mathrm{mL}$. $* p=0.029$; $* * p=0.183$

We then sought to determine whether the reduced IFN- $\alpha$ production from cord blood correlated with a decreased expression of co-stimulatory molecules. In adults, IL-3 alone, a cytokine necessary for the survival of $\mathrm{pDC}$ (15), is sufficient to up-regulate expression of co-stimulatory molecules CD80 and CD86 on pDC from adults (Fig. $3 A$ ). In neonates however, IL-3 alone did not induce adult levels of CD80 and CD86 expression on $\mathrm{pDC}$. We then stimulated $\mathrm{pDC}$ with the maturation-inducing TLR9 agonist $\mathrm{CpG}-\mathrm{B}$. Once stimulated with CpG-B, both adult and neonatal pDC expressed high levels of co-stimulatory markers CD80 and CD86. In fact, the mean fluorescence intensity of CD80 and CD86 was consistently higher on pDC from neonates once stimulated with $\mathrm{CpG}-\mathrm{B}$ (see figure legend and data not shown). Furthermore, the ability of pDC from neonates to respond to the TLR9 agonist was consistent with the expression of adult levels of the TLR9 by neonatal DC (Fig. 3B).

\section{DISCUSSION}

In this study we addressed the hypothesis that pDC from neonates are intrinsically defective. Recent studies in mice suggested that the interaction of neonatal DC with extrinsic factors from neonates, both in vivo and in vitro as a result of mixed-cell populations may play a key role in altering DC function. For example in studies of CD11c + myeloid DC 


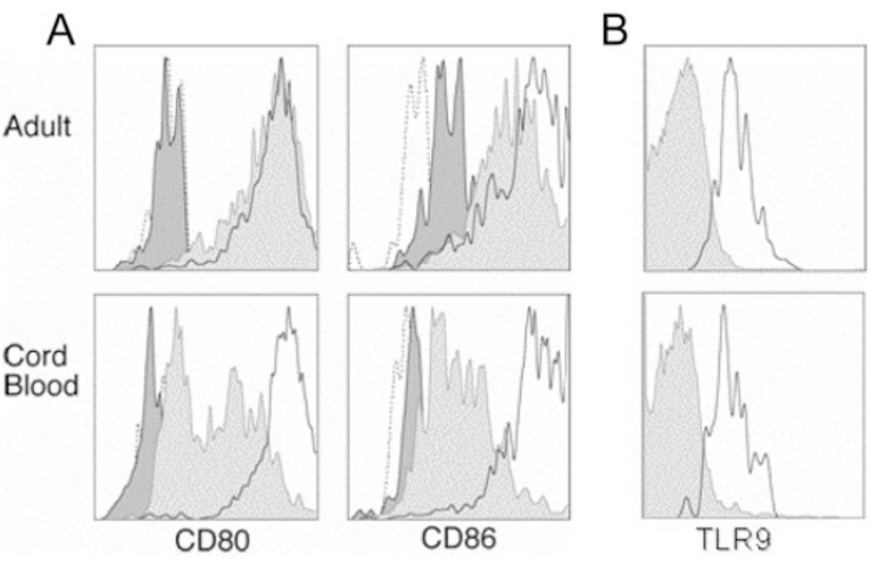

Figure 3. IL-3 alone does not induce adult levels of CD80 and CD86 expression on neonatal $\mathrm{pDC}$ but neonatal $\mathrm{pDC}$ up-regulate co-stimulatory molecules to adult levels after stimulation with CpG-B DNA consistent with their high expression of the TLR9. A) Plots of BDCA-4 bead purified pDC incubated with IL-3 alone or IL-3 and CpG-B DNA for $20 \mathrm{~h}$ are shown. These data are representative of those obtained in four separate experiments studying a total of eight cord blood and four adult blood donors. Cells were stained for expression of CD80 and CD86. The MFI of CD80 expression shown was as follows: adult pDC with IL-3 only $=1525$; adult $\mathrm{pDC}$ with $\mathrm{CpG}-\mathrm{B}=$ 1703; neonate with IL-3 only $=618$; neonate with $\mathrm{CpG}-\mathrm{B}=2487$. The MFI of CD86 expression shown was as follows: adult pDC with IL-3 only $=1077$; adult pDC with CpG-B $=1891$; neonate with IL-3 only $=462$; neonate with CpG-B $=2399$. Isotype control, dashed line; Medium only, dark grey fill; IL-3, light grey fill; and IL-3 + CpG 2006, black line. B) TLR9 expression (black line) was compared with an isotype control (grey fill) in fixed and permeabilized pDC from cord blood and adult blood. Representative plots shown. Identical results were obtained from six cord blood and three adult donors. No change in TLR9 expression was seen in pDC after an overnight stimulation with CpG-DNA (data not shown).

from neonates, non-purified DC in cord blood were defective in stimulating mixed lymphocytes reactions (12), IL-12 production (11), and TLR-induced expression of co-stimulatory molecules $(11,12)$. In contrast, highly purified CD11c+ DC from 1-wk-old mice showed no defect in cell surface expression of co-stimulatory molecules, in their ability to mature in response to LPS (19), to produce IL-12, to produce type I and II interferons in response to TLR agonists (20) or to prime CD8 T-cell responses (19). Similarly, purified CD123+ cells from 1-wk-old mice produced adult levels of IFN- $\alpha$ (14) supporting the idea that DC from neonates may not be intrinsically defective but that extrinsic factors may be responsible for relatively impaired neonatal DC function.

In this report we first compared IFN- $\alpha$ production in $\mathrm{CpG}-$ stimulated whole blood from adults and neonates and found comparable levels of the cytokine. This is in contrast to a report by De Wit et al. who showed that $\mathrm{CpG}$ stimulation of neonatal blood resulted in lower levels of IFN- $\alpha$ compared with adult blood in a small group of donors (18). The relatively large variance between individuals in the amount of IFN- $\alpha$ production in whole blood samples may have prevented detecting a smaller difference between neonates and adults. Unfortunately, De Wit et al. only showed representative data and so we are unable to assess the variance between the small number of donors per group $(n=3)$ in that study. Hence, we cannot directly compare our results to theirs.
Nonetheless, our data demonstrate the absence of any large functional difference between neonate and adult $\mathrm{pDC}$ in whole blood.

To then assess any intrinsic deficiencies, we focused our experiments on purified cells to remove any confounding factors that may arise from the stimulation of non-pDC TLR9expressing cells. Recently, Sun et al. (21) demonstrated that DC from neonates were capable of priming CD4 Th1 responses in adults while the same priming conditions induced CD4 Th2 responses in neonates; this skewed CD4 Th2 response was due to TLR9-responsive IL-10-producing B-cells present in disproportionate numbers in neonates compared with adults. Here, using isolated pDC from neonates we showed that IFN- $\alpha$ production from $\mathrm{pDC}$ from the neonates was lower than from adults. However, the levels produced in neonatal DC were still substantial and it is plausible that this difference may not translate into a biologically relevant deficiency of neonatal pDC compared with adult pDC. Furthermore, an intrinsic deficiency of pDC to up-regulate costimulatory molecules in response to IL-3 could be overcome with TLR9 stimulation.

In summary, pDC from neonates demonstrate an impaired ability to mature and to produce adult levels of IFN- $\alpha$. However, the impaired maturation can be overcome with TLR9 stimulation further highlighting the need to study vaccines in the context of the developing immune system.

Acknowledgments. The authors thank the residents and nurses from the OHSU Labor and Delivery Ward for their support in obtaining cord blood, Dave Lewinsohn for thoughtful reading of the manuscript, and Roger Croteau for obtaining IRB approval for our studies.

\section{REFERENCES}

1. Long SS, Pickering LK, Prober CG 1997 Principles and practice of pediatric infectious diseases. Churchill Livingstone, New York. pp 1-1821

2. Siegrist CA 2000 Vaccination in the neonatal period and early infancy. Int Rev Immunol 19:195-219

3. Adkins B 2000 Development of neonatal Th1/Th2 function. Int Rev Immunol 19:157-171

4. Kadowaki N, Liu YJ 2002 Natural type I interferon-producing cells as a link between innate and adaptive immunity. Hum Immunol 63:1126-1132

5. Hochrein H, Schlatter B, O'Keeffe M, Wagner C, Schmitz F, Schiemann M, Bauer S, Suter M, Wagner H 2004 Herpes simplex virus type-1 induces IFN-\{alpha\} production via Toll-like receptor 9-dependent and -independent pathways. Proc Natl Acad Sci USA 101:11416-11421

6. Lund J, Sato A, Akira S, Medzhitov R, Iwasaki A 2003 Toll-like Receptor 9-mediated Recognition of Herpes Simplex Virus-2 by Plasmacytoid Dendritic Cells. J Exp Med 198:513-520

7. Kadowaki N, Ho S, Antonenko S, Malefyt RW, Kastelein RA, Bazan F, Liu YJ 2001 Subsets of human dendritic cell precursors express different toll-like receptors and respond to different microbial antigens. J Exp Med 194:863-869

8. Bauer S, Kirschning CJ, Hacker H, Redecke V, Hausmann S, Akira S, Wagner H, Lipford GB 2001 Human TLR9 confers responsiveness to bacterial DNA via species-specific CpG motif recognition. Proc Natl Acad Sci USA 98:9237-9242

9. Schlecht G, Garcia S, Escriou N, Freitas AA, Leclerc C, Dadaglio G 2004 Murine plasmacytoid dendritic cells induce effector/memory CD8 + T-cell responses in vivo after viral stimulation. Blood 104:1808-1815

10. Fonteneau JF, Gilliet M, Larsson M, Dasilva I, Munz C, Liu YJ, Bhardwaj N 2003 Activation of influenza virus-specific CD4+ and CD8+ T-cells: a new role for plasmacytoid dendritic cells in adaptive immunity. Blood 101:3520-3526

11. Goriely S, Vincart B, Stordeur P, Vekemans J, Willems F, Goldman M, De Wit D 2001 Deficient IL-12(p35) gene expression by dendritic cells derived from neonatal monocytes. J Immunol 166:2141-2146

12. Hunt DW, Huppertz HI, Jiang HJ, Petty RE 1994 Studies of human cord blood dendritic cells: evidence for functional immaturity. Blood 84:4333-4343 
13. Adkins B, Leclerc C, Marshall-Clarke S 2004 Neonatal adaptive immunity comes of age. Nat Rev Immunol 4:553-564

14. Dakic A, Shao QX, D'Amico A, O'Keeffe M, Chen WF, Shortman K, Wu L 2004 Development of the dendritic cell system during mouse ontogeny. J Immunol 172:1018-1027

15. Grouard G, Rissoan MC, Filgueira L, Durand I, Banchereau J, Liu YJ 1997 The enigmatic plasmacytoid T-cells develop into dendritic cells with interleukin (IL)-3 and CD40-ligand. J Exp Med 185:1101-1111

16. Rissoan MC, Soumelis V, Kadowaki N, Grouard G, Briere F, de Waal Malefyt R, Liu YJ 1999 Reciprocal control of T helper cell and dendritic cell differentiation. Science 283:1183-1186

17. Kerkmann M, Rothenfusser S, Hornung V, Towarowski A, Wagner M, Sarris A, Giese T, Endres S, Hartmann G 2003 Activation with CpG-A and CpG-B oligonu- cleotides reveals two distinct regulatory pathways of type I IFN synthesis in human plasmacytoid dendritic cells. J Immunol 170:4465-4474

18. De Wit D, Olislagers V, Goriely S, Vermeulen F, Wagner H, Goldman M, Willems F 2004 Blood plasmacytoid dendritic cell responses to $\mathrm{CpG}$ oligodeoxynucleotides are impaired in human newborns. Blood 103:1030-1032

19. Dadaglio G, Sun CM, Lo-Man R, Siegrist CA, Leclerc C 2002 Efficient in vivo priming of specific cytotoxic T-cell responses by neonatal dendritic cells. J Immunol 168:2219-2224

20. Sun C-M, Fiette L, Tanguy M, Leclerc C, Lo-Man R 2003 Ontogeny and innate properties of neonatal dendritic cells. Blood 102:585-591

21. Sun CM, Deriaud E, Leclerc C, Lo-Man R 2005 Upon TLR9 signaling, CD5+ B cells control the IL-12-dependent Th1-priming capacity of neonatal DCs. Immunity 22:467-477 